\title{
Eco-friendly Industrial wastewater treatment: Potential of mesophilic bacterium, Pseudomonas putida (ATCC 49128) for hydrogen sulfide oxidation
}

\author{
Mani Malam Ahmad ${ }^{1,2 *}$, Abd. Aziz Mohd Azoddein ${ }^{1}$, Mohammed Saedi Jami ${ }^{3}$
}

${ }^{1}$ Department of Environmental Biotechnology, Faculty of Chemical and Natural Resources Engineering, Universiti Malaysia Pahang, Lebuhraya Tun Razak, 26300 Gambang, Kuantan, Pahang, Darul Makmur, Malaysia, ${ }^{2}$ Department of Biology, Faculty of Science, Kano University of Science and Technology, Wudil, Kano, Nigeria, ${ }^{3}$ Department of Biotechnology Engineering, Faculty of Engineering, International Islamic University, Malaysia, Gombak, 50728, Kuala Lumpur, Malaysia

\section{ARTICLE INFO \\ Article history: \\ Received on: December 23, 2017 \\ Accepted on: January 10, 2018 \\ Available online: April 05, 2018}

\section{Key words:}

Eco-friendly,

Treatment, Sulfide,

Pseudomonas putida,

Potential

\begin{abstract}
The effectiveness and environmental friendliness of biological sulfide oxidation have endeared it to many researchers, mainly for its potential to offer the best alternative for the evacuation of various forms of sulfide. The present study was conducted to assess the potential of gammaproteobacteria, Pseudomonas putida (ATCC 49128), to biodegrade sulfide significantly in a suspended medium of batch reactor type. Sulfide oxidation efficiency was measured spectrophotometrically under defined operational conditions of temperature, agitation, aeration, and influent sulfide concentrations. Sulfide reduction rates were observed at three disproportionate sulfide concentrations of $100 \mathrm{ppm} \mathrm{S}^{2-}$ $\mathrm{L}^{-1} \mathrm{~d}^{-1}, 300 \mathrm{ppm} \mathrm{S}^{2-} \mathrm{L}^{-1} \mathrm{~d}^{-1}$, and $500 \mathrm{ppm} \mathrm{S}^{2-} \mathrm{L}^{-1} \mathrm{~d}^{-1}$. The simple statistical analysis was employed in the interpretation of the data and presented graphically. The results indicated that it was possible to realize sulfide removal efficiency of $45-70 \%$ within the first $6 \mathrm{~h}$ of start-up and $96-100 \%$ in $24 \mathrm{~h}$ period. On the other hand, the corresponding exponential cell growth recorded was $3.91,3.80$, and 3.61 in $100 \mathrm{ppm}, 300 \mathrm{ppm}$, and $500 \mathrm{ppm}$, respectively. This also translates to cell biomass synthesis (cell dry weight) of $0.61 \mathrm{~g} / \mathrm{L}, 0.58 \mathrm{~g} / \mathrm{L}$, and $0.50 \mathrm{~g} / \mathrm{L}$ in 100,500 , and $300 \mathrm{ppm}$, respectively. In conclusion, it can be deduced that this inoculum can utilize different sulfide concentration for its growth and biosynthesis and thus can be employed to treat sulfide contaminated wastewater in a suspended growth form.
\end{abstract}

\section{INTRODUCTION}

Hydrogen sulfide $\left(\mathrm{H}_{2} \mathrm{~S}\right)$, or popularly sulfide, is a notable environmental pollutant considerably produced from numerous domestic and industrial wastewater sources. A toxicity effect of $\mathrm{H}_{2} \mathrm{~S}$ is not restricted to human and environment alone but extended to microbial community capable of degrading it. It is highly toxic compounds that can be formed in an aqueous system which contains both organic matter and sulfate. According to Enning and Garrelfs [1], sulfide buildup in industrial systems may cause several side effects such as corrosion of concrete sewer pipes (mainly, due to microbiologically-induced corrosion by sulfate-reducing bacteria), releasing pungent malodors, toxicity due to sulfide gas, and negative effect on subsequent receiving waters, hence necessitating its mitigation from the surrounding [2].

\footnotetext{
*Corresponding Author:

Mani Malam Ahmad,

Faculty of Chemical and Natural Resources Engineering,

Universiti Malaysia Pahang, Lebuhraya

Tun Razak, 26300 Gambang, Kuantan,

Pahang, Darul Makmur, Malaysia.

Tel.: +601136560301 .

Email:mmahmadu@gmail.com
}

The impacts caused by these industrial pollutants and growing concern for environmental issues have led to the search for new methods of treatment and development of new approaches that are able to reduce sulfide to a permissible discharge level. The classical approach to sulfide removal recorded some tremendous successes, albeit was associated with some set of drawbacks, such as high energy requirements, huge capital investment for handling and maintenance as well as production of secondary pollution [3-6].

However, biological sulfide oxidation (BSO) has the potential to give a perfect different option for the evacuation of low- and high-level sulfide from both fluid and gas streams, alongside the recuperation of sulfur $[7,8]$, which is of greater economic value. Besides, BSO is the cost-effective, efficient, flexible, and more importantly, eco-friendly technology used to treat sulfide-laden wastewater. There are many different approaches to BSO based on immobilized and suspended batch reactor types (BRT).

The present study was therefore set to ascertain the potential of this mesophilic bacterium to BSO, which until now was rarely documented, although some significant discoveries were made related to growth optimization conditioned in different substrates medium. In addition to this, some findings were available in the use of this 
mesophilic bacterium in the treatment of wastewaters laden with phenol, petrochemical effluent, and some heavy metals. Pilot study related to sulfide reduction using synthetic water with exogenous carbon and nutrient sources under defined operational parameters of BRT by Pseudomonas putida against different simulated sulfide concentrations has not been assessed previously. However, simple as it may appear, it is believed that this could serve as an indicator to achieve BSO in a cheap, simple, and eco-friendly approach. Therefore, the finding from this work could be utilized to further sulfide oxidation research studies using this pure culture.

\section{METHODOLOGY}

\subsection{Test Organism and Cultivation}

A pure culture wild-type strain of $P$. putida (ATCC 49128) was used for this study. The nutrient broth was purchased from Merck (Darmstadt, Germany) and prepared according to the manufacturer's instruction. Thereafter, it was sterilized in an autoclave $(\mathrm{H}+\mathrm{P}$ Varioklav Steam Sterilizer ESCO, Japan) at $121^{\circ} \mathrm{C}$ for $15 \mathrm{~min}$, cooled in a water bath to $47^{\circ} \mathrm{C}$, and later dispensed in bottles. The stock culture was maintained throughout the experimental process using a periodic subculture at least fortnightly on nutrient agar (NA) and stored at $4{ }^{\circ} \mathrm{C}$ in a refrigerator until use $[9,10]$. To prepare the pre-culture, 1-3 loopful [11] of cells from a $24 \mathrm{~h}$ actively growing culture on a NA plate was dispensed in bottles containing sterile nutrient broth $(10 \% \mathrm{w} / \mathrm{v})$ and incubated at $37^{\circ} \mathrm{C}$ (Mummert-Germany/BE 600) for $24 \mathrm{~h}$. Afterward, the inoculum was transferred into a $500 \mathrm{ml}$ Erlenmeyer flask containing $150 \mathrm{ml}$ of $30 \% \mathrm{w} / \mathrm{v}$ nutrient broth. The inoculation was aseptically performed in a laminar flow cabinet to avoid contamination, and the flask was sterilized by passing it over a Bunsen flame before and after inoculation. To ensure proper bacterial growth, the inoculation was carried out in triplicates.

\subsection{Media and Synthetic Wastewater}

The media and additional composite exogenous carbon and nutrients sourced formulation were in accordance with the methods described by Fajardo et al. [12], with little modifications. Concisely, the synthetic wastewater contained all the essential constituents for bacterial growth was used. The solution containing in DI water is as follows: $7.5 \mathrm{~g}$ sucrose, 7.5 g NaS.7 $\mathrm{H}_{2} \mathrm{O}, 3.5 \mathrm{~g} \mathrm{NaHCO}_{3}, 3.6 \mathrm{~g} \mathrm{KH}_{2} \mathrm{PO}_{4}, 5.5 \mathrm{~g} \mathrm{NaNO}_{3}$, $5.46 \mathrm{~g} \mathrm{KNO}_{3}$, and $0.08 \mathrm{~g} \mathrm{MgSO}_{4}$. The solutions were thoroughly mixed, and top up with tap water to balance other microelements required, and the $\mathrm{pH}$ was adjusted and maintained at 8.5 using standard buffer solution. In addition, the selected $\mathrm{pH}$ range was found to be an equidistance point where the most reactive sulfide ions existed, hence ensure high oxygen affinity, and thus facilitate for an effective oxidation. Sodium sulfide at a concentration range of 200,300, and $500 \mathrm{ppm}$ was added at a specific time interval of $1 \mathrm{~h}$ after startup to enable that the culture acclimatized to the new environment.

\subsection{Analysis Methods}

For sample analysis, $2.5 \mathrm{ml}$ aliquots were withdrawn periodically at fixed intervals throughout the $8 \mathrm{~h}$ run. Analysis of the samples for the quantification of sulfide depletion was as described elsewhere [13]. The methyl blue method in Hach (2800DR) spectrophotometer was used to analyze sulfide [14].

\subsection{Experimental Setup}

The experiment was conducted in a $2 \mathrm{~L}$ laboratory-scale BRT BIOTRON (LiFlus GX, Intran, Korea). Before startup, the fermenter was stocked with media (with the exception of $\mathrm{Na} 2 \mathrm{~S} .9 \mathrm{H}_{2} \mathrm{O}$ ) and sterilized with the buffer solution and other accessories at $121^{\circ} \mathrm{C}$ for $15 \mathrm{~min}$. After cooling, the calibrated reactor was inoculated with $P$. putida isolate $(150 \mathrm{ml})$ $10 \% \mathrm{v} / \mathrm{v}$. The operation was carried out batch-wisely. The temperature of the medium was maintained at required range using a thermostat water jacket from water bath [15]. Complete homogeneity was maintained inside the reactor with double Rushton mechanical turbine with one foam breaker operated at an agitation of $150 \mathrm{rpm}$. Aeration was achieved using an air compressor (HIBLOW HP-80, Japan) from the reactor base at $50 \mathrm{vvm}$. Furthermore, dissolved oxygen was maintained within the range of $20-5 \mathrm{mg} / \mathrm{l}$ of the least value to the end of the experimental cycle. Thermostat control was used to maintain the temperature of the reactor medium at the optimum of $36^{\circ} \mathrm{C}$ throughout the experimental processes. Likewise, the BRT was operated at a retention time of $24 \mathrm{~h}$ and each experimental cycle with a four periodic sampling for analysis. The oxidation rate of the system was estimated using the Eq. (1).

$R E(\%)=\frac{\Delta S}{S_{0}} * 100$

Where RE is the removal efficiency, $\Delta \mathrm{S}$ is the difference in sulfide concentration gradient between the influent and the sulfide concentration at time $t$, and $\mathrm{S}_{\mathrm{o}}$ is the initial sulfide concentration.

\section{RESULTS AND DISCUSSION}

Results from Figures 1-4 and Tables 1-3 indicated the relative impact of different concentrations of hydrogen sulfide on the growth of $P$. putida (ATCC 49128) measured as exponential cell growth and cell biomass increase (cell dry weight [CDW]). This also corresponds to appreciable sulfide reduction rate and utilization over $24 \mathrm{~h}$ experimentation. The mechanism of electron transport systems involved in BSO is utilized as a source of energy generation and biosynthesis. It was reported that the rate of substrates conversion directly corresponds to increase in cell density [16] which is affected by the sulfide loading rates, oxygen availability, and product types [17], although the kinetic of BSO rate was reported to be a little more independent to oxygen concentration [18]. Microbial cell growth and biomass synthesis through sulfide utilization were shown to be favored more when the equilibrium shifted toward sulfur production, which usually occurs at low oxygen-deficient medium and higher substrates concentration.

An appreciable sulfide utilization indicated by its oxidation was recorded within the first $6 \mathrm{~h}$ of inoculation, with $130 \mathrm{ppm} / \mathrm{h}(65 \%)$, $220 \mathrm{ppm} / \mathrm{h}(73.33 \%)$, and $390 \mathrm{ppm} / \mathrm{h}(78 \%)$ in $200 \mathrm{ppm}, 300 \mathrm{ppm}$, and $500 \mathrm{ppm}$, respectively. This was also compensated by an exponential cell biomass growth range of 2.62-3.91 and cell biomass increase measured by CDW of $0.02-0.59$ cell g/l [Tables $1-3$ ]. The process of biological hydrogen sulfide oxidation to either sulfate or elemental sulfur through dissociation of $\mathrm{H}_{2} \mathrm{~S}$ to $\mathrm{HS}^{-}$or $\mathrm{S}^{2-}$ has been indicated to cause a rise in $\mathrm{pH}$ of the medium, eventually reversing the presumed inhibitory effects and hence resumption of cell growth and sulfide oxidation drastically. Hydrogen sulfide serves as an electron donor during the oxidation process, as well as a substrate to the biodegrading consortium in addition to its role as the primary nutrient source. Depending on the concentration level, sulfide tends to be inhibitory to the isolates growth, especially at high level, although this could be taken care of through oxygen dosing rate.

Furthermore, BSO and cell biomass increase was consistently significant and sustained through the $24 \mathrm{~h}$ period in all the three different concentrations. Consequently, sulfide was significantly reduced by $190 \mathrm{ppm} / \mathrm{h}(95 \%), 285 \mathrm{ppm} / \mathrm{h}$ (95\%), and $495 \mathrm{ppm} / \mathrm{h}(99 \%)$, 
Table 1: Growth and sulfide oxidation of P. putida (ATCC 49128) in $200 \mathrm{ppm}$

\begin{tabular}{|c|c|c|c|c|c|c|}
\hline Time & OD $(600 \mathrm{~nm})$ & CDW & Exponential cell growth & $\mathrm{H}_{2} \mathrm{~S}$ red. rate & $\mathrm{H}_{2} \mathrm{~S}$ removal & ppm $\mathrm{H}_{2} \mathrm{~S} / \mathrm{g}$ cell \\
\hline 0 & 0.03 & 0.00 & 0.00 & 200 & 0.00 & 0.00 \\
\hline 1 & 0.06 & 0.02 & 0.69 & 115 & 42.5 & 5,700 \\
\hline 12 & 0.8 & 0.31 & 3.28 & 110 & 45 & 350 \\
\hline 18 & 1.5 & 0.59 & 3.91 & 50 & 75 & 80 \\
\hline
\end{tabular}

P. putida: Pseudomonas putida, CDW: Cell dry weight

Table 2: Growth and sulfide oxidation of P. putida (ATCC 49128) in $300 \mathrm{ppm}$

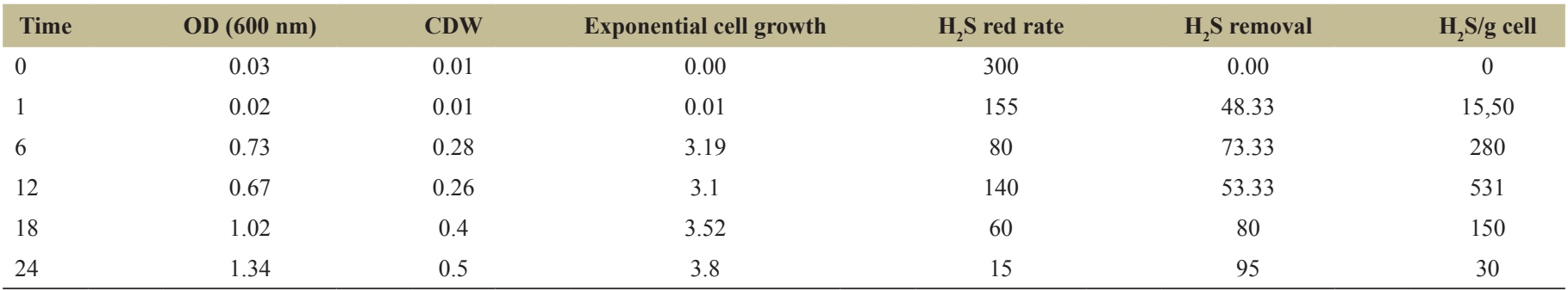

P. putida: Pseudomonas putida, CDW: Cell dry weight

Table 3: Growth and sulfide oxidation of P. putida (ATCC 49128) in $500 \mathrm{ppm}$

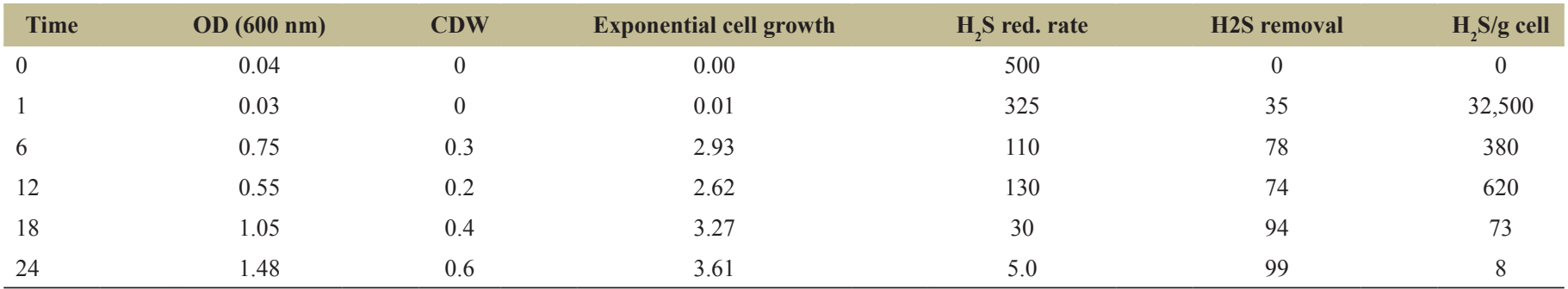

P. putida: Pseudomonas putida, CDW: Cell dry weight

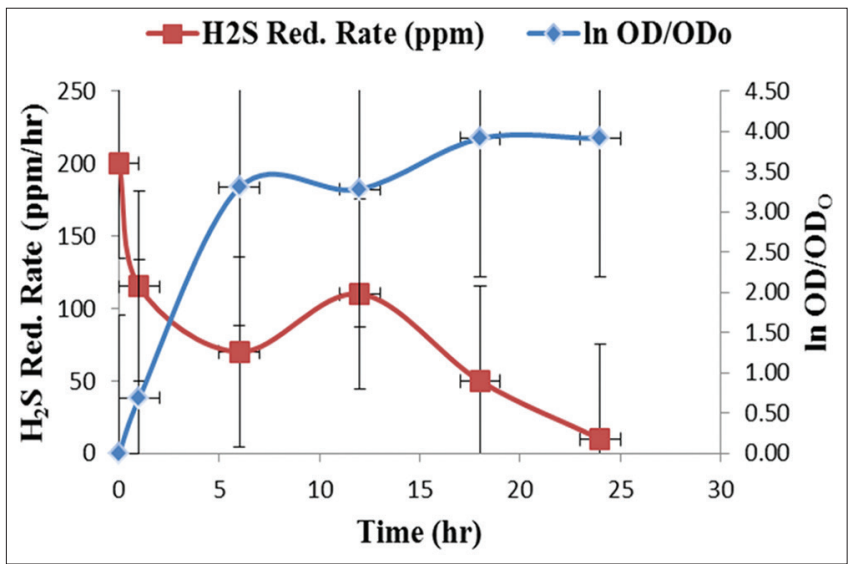

Figure 1: Pseudomonas putida (ATCC 49128) growth and removal in 200 ppm sulfide concentration.

in $200 \mathrm{ppm}, 300 \mathrm{ppm}$, and $500 \mathrm{ppm}$, respectively [Figure 4]. This sulfide oxidation also corresponds to highest rates of growth observed [Figures 1-3 and Tables 1-3]. It was reported that microaerobic nature (low oxygen dosing level) coupled with high sulfide concentration facilitate sulfur formation $[19,20]$, and this was further affirmed in the finding by [21], who suggested that high substrate concentration and low oxygen level favored sulfur selectivity. Overall, BSO was

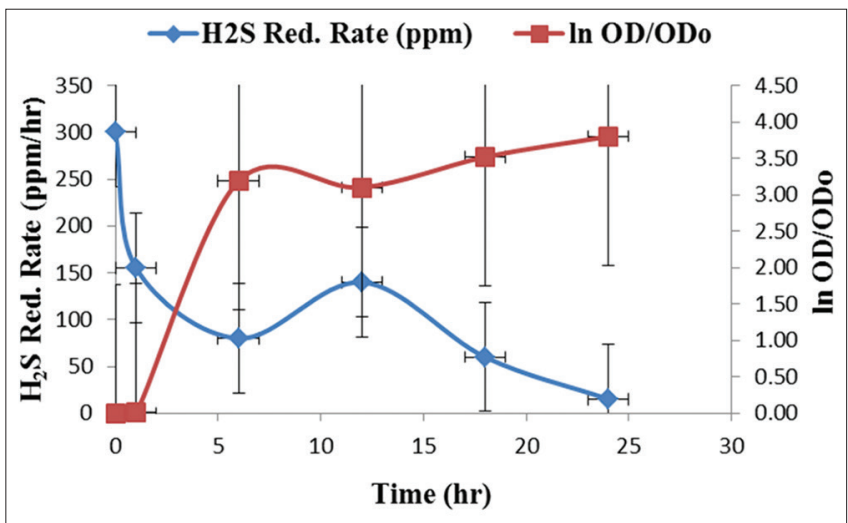

Figure 2: Pseudomonas putida (ATCC 49128) growth and removal in 300 ppm sulfide concentration.

consistent in all the three different concentrations, although with some few variations probably due to the impact of the substance on metabolic activities of the isolate. This assertion could be deduced from the sulfide reduction rate in relation to cell biomass accumulation (CDW), which is given as the ratio of concentration sulfide to cell biomass ( $\mathrm{ppm} \mathrm{H}_{2} \mathrm{~S} / \mathrm{g}$ cell). This inverse relationship indicated an increase in CDW as sulfide concentration is further depleted, probably signaling sulfide uptake, and assimilation by the growing and dividing 


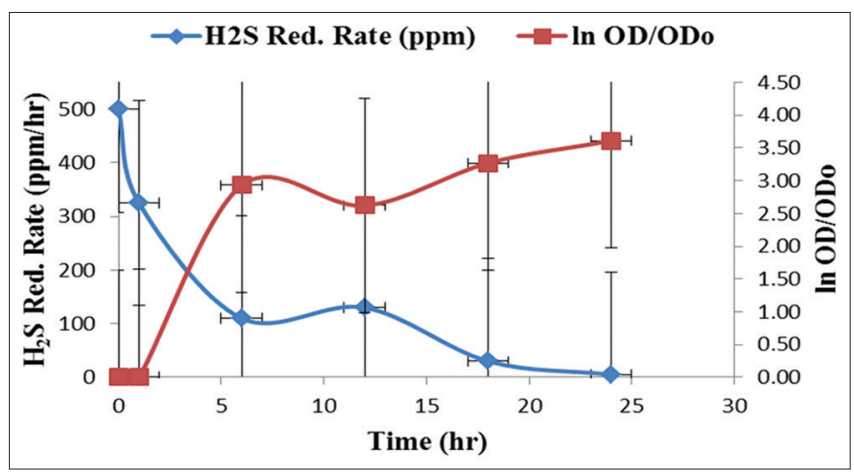

Figure 3: Pseudomonas putida (ATCC 49128) growth and removal in 500 ppm sulfide concentration.

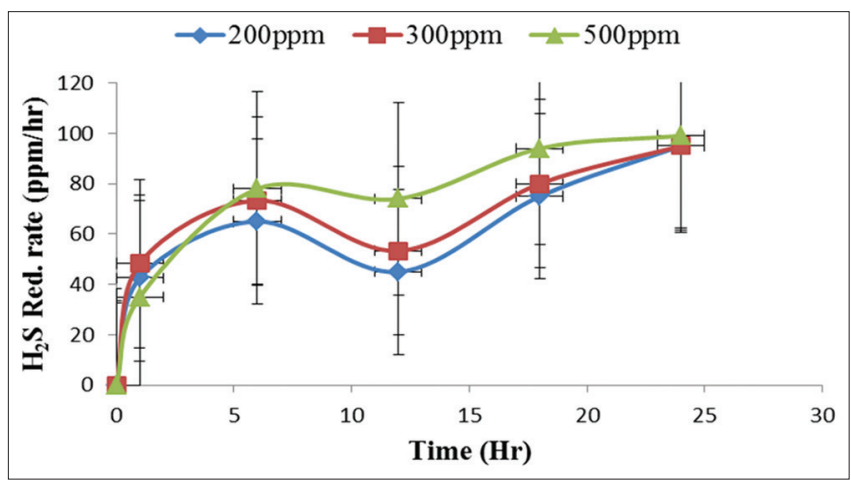

Figure 4: Sulfide removal rate at different concentration over $24 \mathrm{~h}$ period.

cells [Tables 1-3]. This finding is supported by the studies of Bin Mohd Azoddein et al. and Mosquera et al. [22,23].

It was reported that $\mathrm{BSO}$ used to be a self-spontaneous process which used to be as fast as other biological reactions. However, the rate of BSO is dependent on $\mathrm{pH}$, the concentration of the reactants $\left(\mathrm{H}_{2} \mathrm{~S} / \mathrm{SO}_{4}{ }^{2-}\right)$, as well as the presence of catalyzing heavy metals [23]. The $\mathrm{pH}$ mainly determines the product type, elemental sulfur, thiosulfate, or sulfite as well as sulfide within the range $>7$ or less. Biological oxidation of sulfide is an energy-yielding mechanism, where more energy is generated in sulfide oxidation to sulfur than oxidation of elemental sulfur to sulfate. The rates of sulfide reduction seem to proceed faster at lower concentration [12] compared to higher concentration. However, higher sulfide concentration can become inhibitory [24], at a certain stage as well as lead to large residual metabolites. However, on exhaustion of sulfide, chemolithotrophic bacteria (BSO) use sulfur as an alternative source of energy with the expression of sulfur-oxidizing ability (sox) gene cluster system [25]. These are a collection of genes that allow the isolate to utilize sulfur in vitro in the absence of sulfide. Furthermore, sulfide biological oxidation and cell biomass synthesis increase consistently through the 24 hour period in all the three different concentrations. Furthermore, a synergistic comparative cell growth and sulfide oxidation (i.e., reduction in sulfide concentration) clearly demonstrated utilization of sulfide for biomass synthesis [Figure 1-3]. Therefore the relationship between sulfide utilization and growth agrees with Monod growth model for microbial cell and related literature [26,27].

\section{CONCLUSIONS}

P. putida (ATCC 49128), has been known for its biodegradability potential of both domestic and refractory industrial wastewater. But its application directly to sulfide oxidation was not so much popular. Despite the hypoxic nature of the experimented medium, the suitability of this strain to sulfide bioremediation process was undisputable, manifested by high rate of sulfide depletion of $99 \%$ in $500 \mathrm{ppm}$ sulfide, $95 \%$ in $300 \mathrm{ppm}$ and $200 \mathrm{ppm}$, within 24 hour period respectively. Furthermore, this strain displayed its reliability in reducing sulfide level within the first six hours by $78 \%$ in 500 ppm, $73 \%$ in $300 \mathrm{ppm}$ and $65 \%$ in $200 \mathrm{ppm}$, respectively. On the other hand, overall cell exponential growth was contrastingly higher in $200 \mathrm{ppm}$ with 3.91 , followed by $3.80300 \mathrm{ppm}$ and 3.61 in $500 \mathrm{ppm}$. While bacterial cell dry weight followed the same pattern with $0.61 \mathrm{~g} / \mathrm{L}, 0.58 \mathrm{~g} / \mathrm{L}$ and $0.50 \mathrm{~g} / \mathrm{L}$ in $200 \mathrm{ppm}, 500 \mathrm{ppm}$, and $300 \mathrm{ppm}$, respectively. But the reason behind this abnormal trend was not quite understood. Although it was probably due to the limited inhibitory effect of sulfide, which allowed for faster growth in $200 \mathrm{ppm}$, over the other ranges, since it is the only varying limiting factor

\section{ACKNOWLEDGMENTS}

The authors wish to acknowledge the management of University Malaysia Pahang (UMP) for their financial support through a local research grant (PGRS).

\section{REFERENCES}

1. Enning D, Garrelfs J. Corrosion of iron by sulfate-reducing bacteria: New views of an old problem. Appl Environ Microbiol 2014;80:1226-36.

2. Zytoon MA, AlZahrani AA, Noweir MH, El-Marakby FA. Bioconversion of high concentrations of hydrogen sulfide to elemental sulfur in airlift bioreactor. Hindawi Publ Corp Sci World J 2014;2014:675673.

3. Kim JH, Rene ER, Park HS. Biological oxidation of hydrogen sulfide under steady and transient state conditions in an immobilized cell biofilter. Bioresour Technol 2008;99:583-8.

4. Guerreroa L, Cesar Huilinir SM, Campos JL, Andrea Barahona RB. Advances in the biological removal of sulphides from aqueous phase in anaerobic processes : A review. Environ Rev 2015;24:1-61.

5. Azizana NH, Apunb KA, Bilungb LM, Vincentb M, Roslanb HA, Sallehin AA, et al. Crude oil bioremediation by indigenous bacteria isolated from oily sludge. J Teknol 2016;2:61-6.

6. Tang K, Baskaran V, Nemati M. Bacteria of the sulphur cycle: An overview of microbiology, biokinetics and their role in petroleum and mining industries. Biochem Eng J 2009;44:73-94.

7. Liang Z, An T, Guiying Li ZZ. Aerobic biodegradation of odorous dimethyl disulfide in aqueous medium by isolated Bacillus cereus GIGAN2 and identification of transformation intermediates. Bioresour Technol 2015;175:563-8.

8. Reshma JK \& AM. Biodegradation of phenol-aerobic and anaerobic pathways. Int J Sci Nat 2014;5:366-87.

9. Rashedi H, Ali Izadi ME. Optimization of operational parameters in rhamnolipid production by Pseudomonas aeruginosa MM1011 in a miniaturized shaken bioreactor. J Appl Biotechnol Reports 2015;2:271-8.

10. Wang SJ, Loh KC. Modeling the role of metabolic intermediates in kinetics of phenol biodegradation. Enzyme Microb Technol 1999;25:177-84.

11. Durve A, Chandra N. FT-IR analysis of bacterial biomass in response to heavy metal stress. Int J Biotechol 2014;112:386-91.

12. Fajardo C, Mosquera-Corral A, Campos JL, Mendez R. Autotrophic denitrification with sulphide in a sequencing batch reactor. Environ Manage 2012;113:552-6.

13. Kleinjan WE, de Keizer A, Janssen AJ. Equilibrium of the reaction between dissolved sodium sulfide and biologically produced sulfur. 
Colloids Surf B Biointerfaces 2005;43:228-37.

14. Wang X, Zhang Y, Zhang T, Zhou J. Effect of dissolved oxygen on elemental sulfur generation in sulfide and nitrate removal process: Characterization, pathway, and microbial community analysis. Appl Microbiol Biotechnol 2016;100:2895-905.

15. Moghanloo GM, Fatehifar E, Saedy S, Aghaeifa Z, Abbasnezhad H. Biological oxidation of hydrogen sulfide in mineral media using a biofilm airlift suspension reactor. Bioresour Technol 2010;101:8330-5.

16. Mora M, Fernández M, Gómez JM, Cantero D, Lafuente J, Gamisans X, et al. Kinetic and stoichiometric characterization of anoxic sulfide oxidation by SO-NR mixed cultures from anoxic biotrickling filters. Appl Microbiol Biotechnol 2015;99:77-87.

17. Alcantara S, Velasco A, Muñoz A, Cid J, Revah S, Razo-Flores E, et al. Hydrogen sulfide oxidation by a microbial consortium in a recirculation reactor system: Sulfur formation under oxygen limitation and removal of phenols. Environ Sci Technol 2004;38:918-23.

18. Nielsen AH, Vollertsen J, Hvitved-Jacobsen T. Kinetics and stoichiometry of aerobic sulfide oxidation in wastewater from sewerseffects of $\mathrm{pH}$ and temperature. Water Environ Res 2006;78:275-83.

19. Janssen AJ, Lettinga G, De Keizer A. Removal of hydrogen sulphide from wastewater and waste gases by biological conversion to elemental sulphur. Colloidal and interfacial aspects of biologically produced sulphur particles. Coll Surf A Physicochem Eng Asp 1999;151:389-97.

20. Liu H, Wang M, Huang Z, Du H, Tang H. Study on biological control of microbiologically induced corrosion of carbon steel. Mater Corrosion 2004;55:387-91.

21. van den Bosch PL, de Graaff M, Fortuny-Picornell M, van
Leerdam RC, Janssen AJ. Inhibition of microbiological sulfide oxidation by methanethiol and dimethyl polysulfides at natronalkaline conditions. Appl Microbiol Biotechnol 2009;83:579-87.

22. Bin Mohd Azoddein AA, Mani Malam Ahmad RM, Sulaiman NM. A bioremediation approach to mercury removal in a shake flask culture using Pseudomonas putida (ATCC 49128). J Anal Bioanal Tech 2016;7:312.

23. Mosquera S, González-Jaramillo LM, Orduz S, Villegas-Escobar V. Multiple response optimization of Bacillus subtilis EA-CB0015 culture and identification of antifungal metabolites. Biocatal Agric Biotechnol 2014;3:378-85.

24. Qaisar M, Ping Z, Jing C, Yousaf H, Jaffar HM, Wu Dong-lei HB. Sources of sulfide in waste streams and current biotechnologies for its removal. Zhejiang 2007;8:1126-40.

25. Cornelius GF, Dagmar R, Frank B, Armin FJ. Oxidation of reduced inorganic sulfur compounds by bacteria: Emergence of a common mechanism? Appl Environ Microbiol 2001;67:2873-82.

26. Monod J. The growth of bacterial cultures. Annu Rev Microbiol 1949;3:371-94.

27. Okpokwasili GC, Nweke CO. Microbial growth and substrate utilization kinetics. Afr J Biotechnol 2005;5:305-17.

\section{How to cite this article:}

Ahmad MM, Azoddein AAM, Jami MS. Eco-friendly Industrial wastewater treatment: Potential of mesophilic bacterium, Pseudomonas putida (ATCC 49128) for hydrogen sulfide oxidation. J App Biol Biotech. 2018;6(3):53-57. DOI: 10.7324/JABB.2018.60309 